\title{
Substorm observations in the early morning sector with Equator-S and Geotail
}

\author{
R. Nakamura ${ }^{1}$, G. Haerendel ${ }^{1}$, W. Baumjohann ${ }^{1}$, A. Vaivads $^{1}$, H. Kucharek ${ }^{1}$, B. Klecker ${ }^{1}$, E. Georgescu ${ }^{1,2}$, J. Birn ${ }^{3}$, \\ L. M. Kistler ${ }^{4}$, T. Mukai ${ }^{5}$, S. Kokubun ${ }^{6}$, P. Eglitis ${ }^{7,8}$, L. A. Frank ${ }^{9}$, J. B. Sigwarth ${ }^{9}$ \\ ${ }^{1}$ Max-Planck-Institut für extraterrestrische Physik, Garching, Germany \\ ${ }^{2}$ Institut for Space Sciences, Bucharest, Romania \\ ${ }^{3}$ Los Alamos National Laboratory, USA \\ ${ }^{4}$ Space Science Center, University of New Hampshire, USA \\ ${ }^{5}$ Institut for Space and Astronautical Science, Sagamihara, Japan \\ ${ }^{6}$ Solar-Terrestrial-Environment Laboratory, Nagoya University, Japan \\ ${ }^{7}$ Swedish Institute of Space Physics, Uppsala, Sweden \\ ${ }^{8}$ Finnish Meteorological Institute, Helsinki, Finland \\ ${ }^{9}$ Department of Physics and Astronomy, University of Iowa, USA
}

Received: 12 May 1999 / Revised: 13 July 1999 / Accepted: 20 July 1999

\begin{abstract}
Data from Equator-S and Geotail are used to study the dynamics of the plasma sheet observed during a substorm with multiple intensifications on 25 April 1998, when both spacecraft were located in the early morning sector (03-04 MLT) at a radial distance of 10$11 R_{E}$. In association with the onset of a poleward expansion of the aurora and the westward electrojet in the premidnight and midnight sector, both satellites in the morning sector observed plasma sheet thinning and changes toward a more tail-like field configuration. During the subsequent poleward expansion in a wider local time sector (20-04 MLT), on the other hand, the magnetic field configuration at both satellites changed into a more dipolar configuration and both satellites encountered again the hot plasma sheet. High-speed plasma flows with velocities of up to $600 \mathrm{~km} / \mathrm{s}$ and lasting 2-5 min were observed in the plasma sheet and near its boundary during this plasma sheet expansion. These high-speed flows included significant dawn-dusk flows and had a shear structure. They may have been produced by an induced electric field at the local dipolarization region and/or by an enhanced pressure gradient associated with the injection in the midnight plasma sheet.
\end{abstract}

Key words. Magnetospheric physics (magnetospheric configuration and dynamics; plasma sheet; storms and substorms)

Correspondence to: R. Nakamura

e-mail: rumi@mpe.mpg.de

\section{Introduction}

The dynamics in the near-Earth region (inside $15 R_{E}$ ) is expected to be controlled by dipolarization and formation of the current wedge. At expansion onset, the magnetic field returns to a more dipolar configuration and the plasma sheet expands within a longitude range that is spanned by the substorm current wedge (McPherron et al., 1973). Observations of magnetic fields at geosynchronous orbit showed that the disruption of the tail current occurs initially in the longitudinally localized region causing a field change to a dipolar orientation in the corresponding region, whereas outside the current disruption regions the field becomes more tail-like (Nagai, 1982b, 1991). The current wedge and associated dipolarization of the field expand in longitude both eastward and westward (Nagai, 1982a, b, 1991; Arnoldy and Moore, 1983). It has been shown that eastward expansion into the morning sector is less likely to happen than the westward expansion into the evening sector (Arnoldy and Moore, 1983).

Statistical studies of the fast flows associated with substorm expansion phase showed that high-speed convection flows are concentrated in the premidnight region (Nagai and Machida, 1998). The local time distribution is consistent with the center of the current wedge region, which was obtained to be located around 23 MLT (Nagai, 1991). Probability of the high speed flow significantly decreases earthward of $15 R_{E}$ (Baumjohann, 1993), although a detailed case study indicated that at times significant high speed flows exist also in the near-Earth region $\left(\begin{array}{ll}10 & R_{E}\end{array}\right)$ associated with substorms (Fairfield et al., 1998).

Several studies have reported plasma sheet thinning in the early morning sector during the recovery phase of substorms with multiple intensifications which could be 
different than the usual plasma sheet thinning during the growth phase in the night sector. Popielawska et al. (1996) reported periods of recurrent plasma sheet thinning about an hour after the main onset in the 8$11 R_{E}$ region due to access of the plasma mantle to the central plasma sheet under strong IMF input. Plasma sheet thinning in the early morning sector was also observed near the geosynchronous orbit (Kopanyi and Korth, 1995) during the substorm recovery phase.

In this study we examine the response of the early morning plasma sheet to a substorm, which started initially in the premidnight sector and expanded in longitude during the course of three intensifications. Two spacecraft, Equator-S and Geotail, separated by about $1 \mathrm{~h}$ in LT, monitored the disturbance above and below the equatorial plane. High-speed flow disturbances were detected in association with the substorm expansion in the early morning sector. We discuss the possible deformation of the plasma sheet in the morningside in the course of substorm evolution and how these high-speed flows could evolve in the early morning sector.

\section{Observations}

A substorm with maximum $A E$ of $700 \mathrm{nT}$ commenced at 0205 UT on 25 April 1998, with three main intensifications in the night sector. Figure 1 shows the distributions of the ground-based stations in the nightside sector together with the estimated foot point of Geotail and Equator-S in corrected geomagnetic coordinates. The location of the foot point is obtained using the Tsyganenko 89 model for $K p=3$ (Tsyganenko, 1989). The foot point of Equator-S was located close to the meridian of the International Monitor for Auroral Geomagnetic Effects (IMAGE; Lühr, 1994) stations,

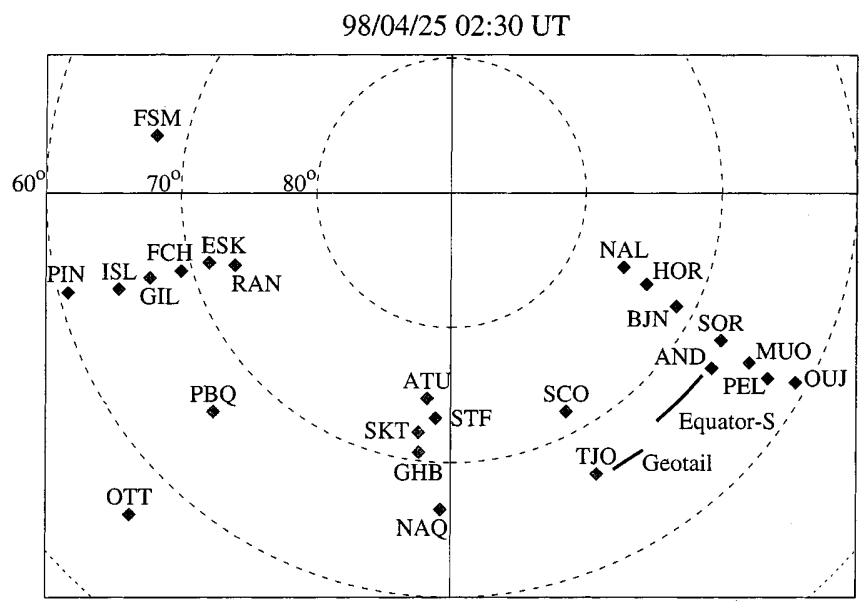

00 MLT

Fig. 1. Distribution of the ground-based stations in the nightside sector together with the estimated foot point of Geotail and Equator-S in corrected geomagnetic coordinates. Positions are shown so that local midnight for 0230 UT is directed downward in the figure. The location of the foot point was obtained using the Tsyganenko 89 model for 0200 and 0300 UT whereas that of Geotail was located close to Tjornes (TJO).

\subsection{Nightside ground-based observations}

Selected ground magnetic records from auroral zone stations in the premidnight to morning sector are shown in Fig. 2a. Mid-latitude magnetograms and magnetograms from Canadian Auroral Network for the OPEN program Unified Study (CANOPUS; Rostoker et al., 1995) chain are shown in Fig. 2b and c, respectively. Magnetograms from the Greenland/Iceland chains in the midnight and postmidnight sector are shown in Fig. 2d. The vertical lines indicate 0205, 0216, 0232, and 0239 UT. An enhancement in the westward electrojet up to $250 \mathrm{nT}$ started at Poste-de-la-Baleine (PBQ) at 0205 UT (see Fig. 2a) together with the positive bay at Ottawa (OTT, Fig. 2b). This activation was confined to the premidnight sector. The second activation occurred at 0216 UT at the CANOPUS stations in the premidnight sector as well as at Narsarsuaq (NAQ) in the midnight sector. A more global activation was then observed starting at 0232 UT at Gillam (GIL) and Fort Churchill $(\mathrm{PCH})$ with a global poleward expansion, which included the premidnight CANOPUS chain, and the midnight and post-midnight Greenland/Iceland chains. The 0232 UT activation was followed by an electrojet enhancement in the early morning sector (see AND and SOR in Fig. 2a) and subsequent poleward expansion starting at $0239 \mathrm{UT}$, as will be further discussed in the next section.

\subsection{Early-morning sector ground-based observations}

Figure 3 shows (a) the IMAGE chain magnetograms and (b) the power and the line-of-sight velocity data from the Scandinavian Twin Auroral Radar Experiment (STARE; Greenwald et al., 1978) overlapped with the equatorward and poleward boundary of the westward electrojet (dotted lines). The boundaries of the electrojets are determined from the latitudinal distribution of $X$ (north) and $Z$ (downward) magnetic field components along the meridian in the IMAGE chain. The radar data are from Finland beam 1 and positive velocities are towards the radar, which includes eastward plasma flow. Westward electrojet due to Hall-current is expected to produce eastward electron drift observed by radar. After 214 UT, the westward electrojet region moved equatorward. The region of the center of the positive line-ofsight velocity also followed the motion of the elctrojet boundary. At 0232 UT, the positive velocity increased and the region of enhanced velocity moved further equatorward. At 0239 UT, the positive velocity increased again and the region of the enhanced velocity moved poleward together with the boundary of the westward electrojet.

In summary, while the 0205 UT onset was confined to the premidnight sector, the 0216 UT and 0232 onsets involve westward electrojet evolution and equatorward 
980425

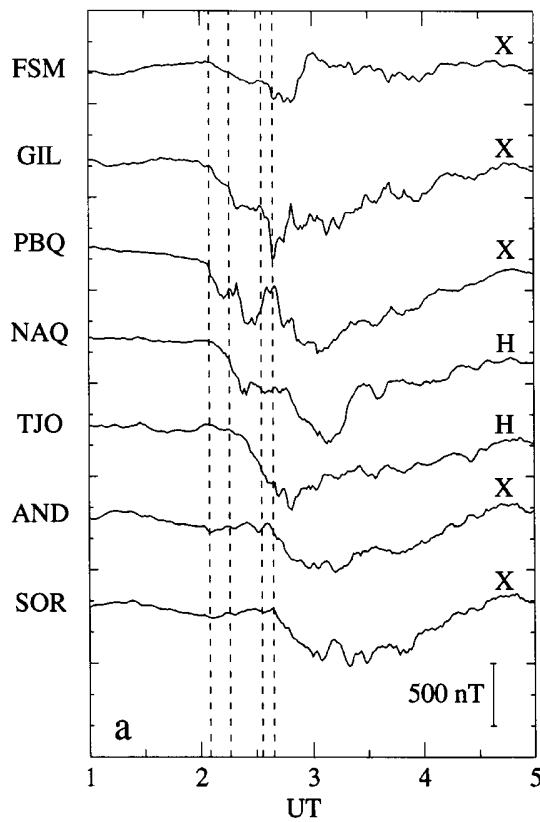

X-component
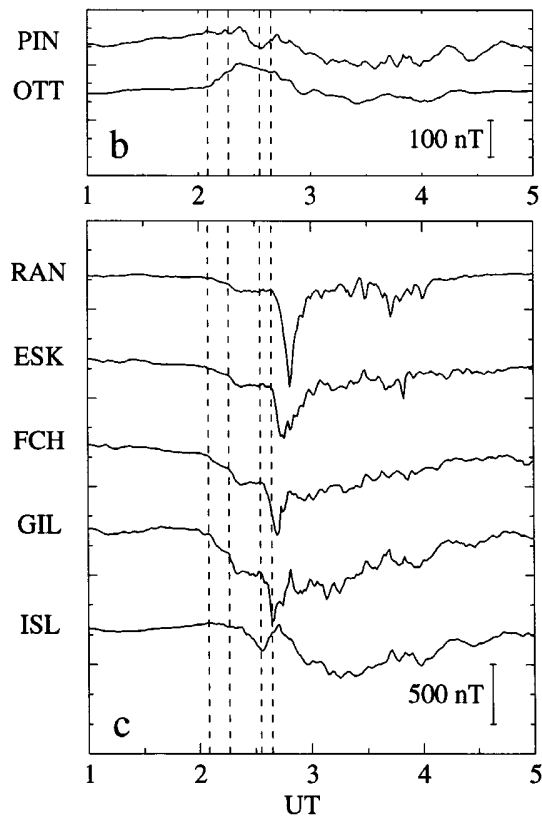

H-component

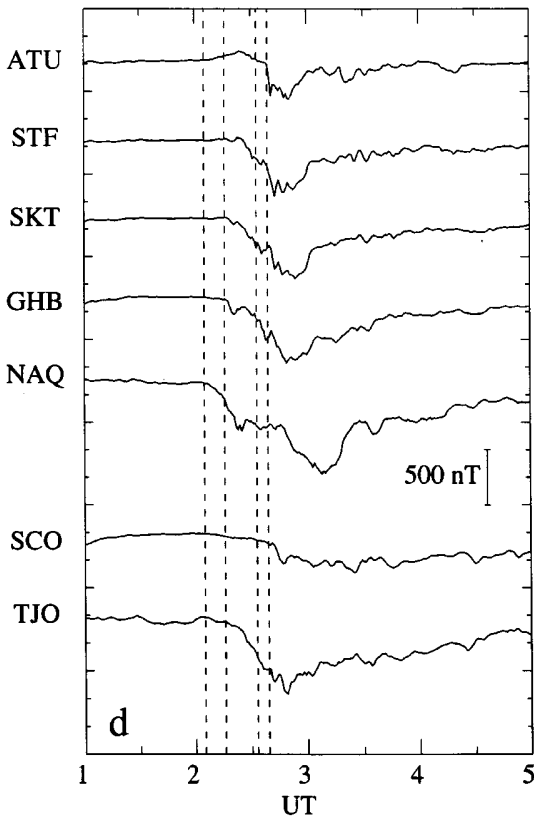

Fig. 2. a Selected ground magnetic records from auroral zone stations in the premidnight, midnight, and early morning sectors. b Mid-latitude magnetograms and $\mathbf{c}$ high-latitude magnetograms in the premidnight sector. d Magnetograms from the Greenland/Iceland chains in the midnight and postmidnight sectors. The vertical lines indicate $0205,0216,0232$, and 0239 UT motion of the electrojet center in the morning sector. Followed by an electrojet enhancement in the premidnight/postmidnight sector, activation and poleward expansion of the electrojet occurred also in the early morning sector from 0239 UT onwards.

\subsection{Auroral observations}

Sequences of global auroral images during the substorm obtained by the visible imaging system (VIS) imager (Frank et al., 1995), onboard Polar spacecraft are shown in Fig. 4. Initial brightening occurred at 0205 UT in the premidnight, which coincides with the 0205 UT onset in the electrojet. In accordance with the spatial distribution of the electrojet, this auroral activation was confined in the premidnight sector. Following the 0216 UT electrojet onset, poleward expansion in the premidnight/midnight sector and expansion of bright region of aurora toward postmidnight (02 MLT) occurred. Whereas the aurora in the premidnight stayed intense, the aurora in the postmidnight became diffuse by 0231 UT. Another intensification in the premidnight are occurred at around 0236 UT followed by further poleward expansion of aurora in a wide local time sector extending between 20 MLT and 04 MLT. Auroral activation and poleward expansion can be identified also in the early morning sector (04 MLT) after 0239 UT.

\subsection{Morningside plasma sheet observations}

Figure 5 shows the location of Geotail and Equator-S in Solar-magnetic (SM) coordinates between 0200 and
0400 UT. Equator-S has a $500 \mathrm{~km} \times 11.5 R_{E}$ nearequatorial orbit, whereas Geotail has a low-inclination $10 \times 30 R_{E}$ orbit. The configuration of these two satellites allowed conjunction events near the Equator-S apogee. The data used in this study are from one of the conjunction passes. During the substorm discussed in this study, Geotail was located in the southern hemisphere, whereas Equator-S is located in the northern hemisphere and closer to the equatorial plane. The Equator-S data used in the present study are $20 \mathrm{~s}$ averaged data from the magnetic field instrument (Fornacon et al., 1999) and preliminary moment data from the ion composition instrument (Kistler et al., 1999) calculated on ground from the 3D distribution function. We use 12-s-averaged data from the Geotail magnetic field experiment (Kokubun et al., 1994) and the low energy particle experiment (Mukai et al., 1994).

Figure 6 shows Geotail magnetic field and plasma data for the interval between 0210 and 0300 UT. Dotted lines accompanying the magnetic field are calculated using the Tsyganenko 89 model for $K p=3$. Instead of using the actual $K p$ for this interval, which was 5, we chose this $K p=3$ model as more typical one for nonsubstorm times. At $\sim 0210$ UT the actual magnitude of the field was larger than given by the model, but the azimuth, $\phi$, and polar angle, $\theta$, are only several degrees smaller than the model values, which could be due to a more intense tail current than expected from the model. Figure 7 shows Equator-S magnetic field and plasma data in the same format as Fig. 6. Equator-S, located further dawnside, observed lower $\theta$ than expected from the model. This could be due to an enhanced tail current tailward of the satellite. Magnetic field signatures at both spacecraft until about 0215 UT could therefore 


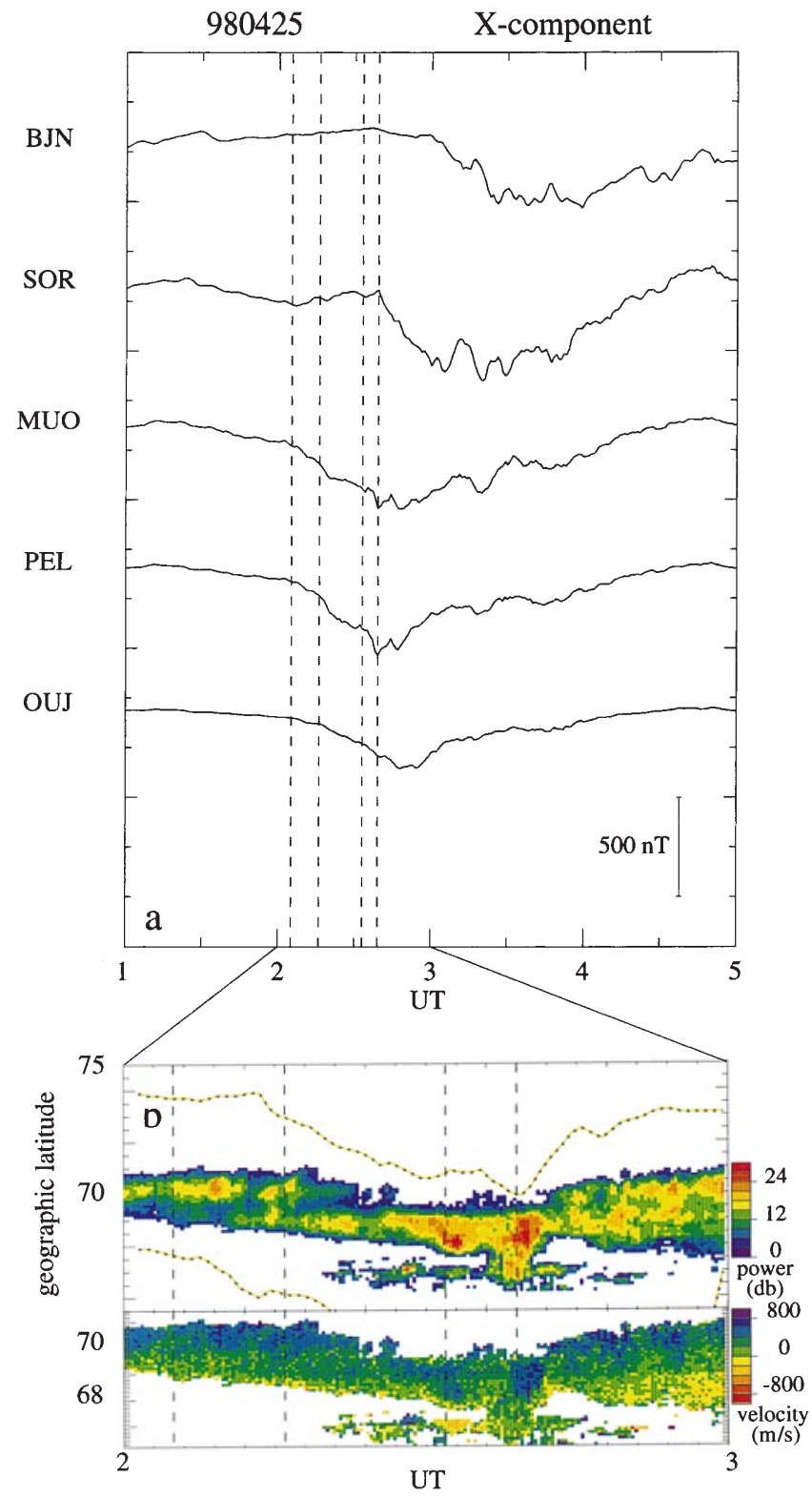

Fig. 3. a The IMAGE chain magnetograms and $\mathbf{b}$ the power and the line-of-sight velocity data from STARE data overlapped with the equatorward and poleward boundary of the westward electrojet (dotted lines)

indicate an intensified tail current compared to the nonsubstorm times.

The magnetic field magnitude showed a gradual increase for both satellites after 0215 UT. Geotail observed a decrease in temperature between 0215 UT and $0242 \mathrm{UT}$, which was consistent with the satellite moving away from the hot plasma sheet. Equator-S, which was located in the opposite hemisphere, observed also a decrease in the temperature in phase with the increase in magnetic field between 0231 UT and 0238 UT, which indicates exiting the hot plasma sheet. These signatures therefore suggest the thinning of the plasma sheet. The most significant change in the magnetic field, however, was the decrease in $\phi$ for both satellites. This change is due to an additional westward

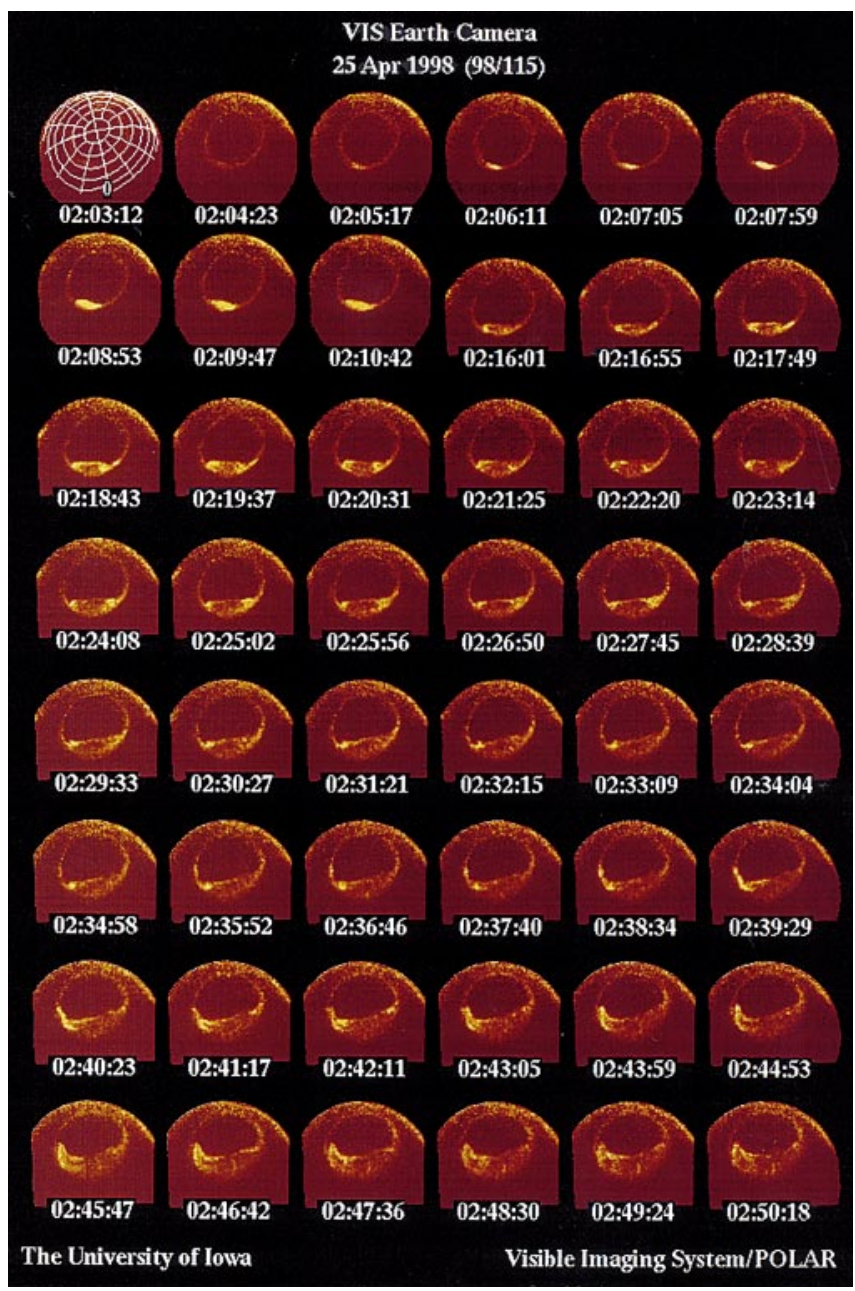

Fig. 4.

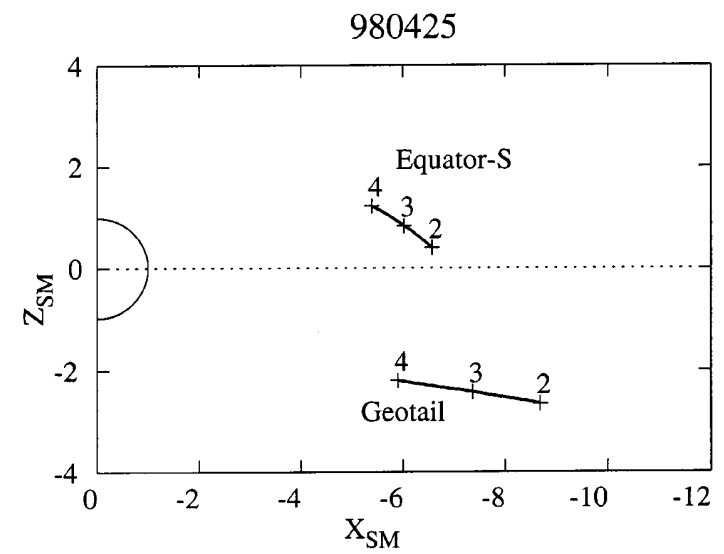

Fig. 5. The location of Geotail and Equator-S in Solar-magnetic (SM) coordinates between 0200 and 0400 UT

component for Geotail (located in the southern hemisphere) so that the magnetic field azimuth approached to tailward direction $\left(\phi=180^{\circ}\right)$. Major change in $\phi$ was also observed at Equator-S (located in the northern hemisphere) between 0215 UT and 0231 UT, which is due to an additional eastward component rotating the magnetic field toward sunward direction $\left(\phi=0^{\circ}\right)$. 


\section{GEOTAIL $\quad 980425$}

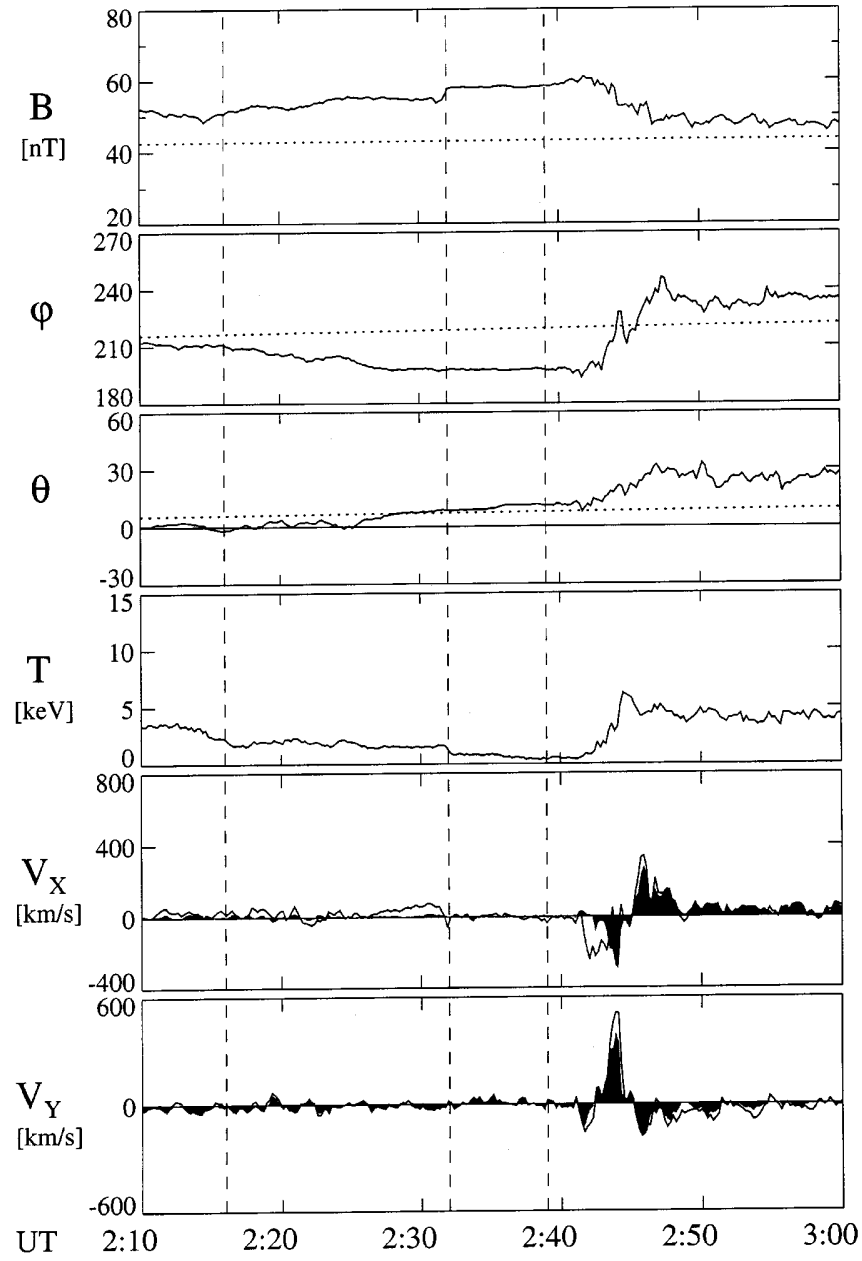

Fig. 6. Magnetic field and plasma data from Geotail between 0210 and 0300 UT. Shown are magnitude, azimuth $(\phi)$ and polar angle $(\theta)$ of the magnetic field, ion temperature, and $X$ and $Y$ components of the ion flow velocity in SM coordinates. Dotted lines accompanying the magnetic field data show values obtained from the Tsyganenko 89 model. The velocity components perpendicular to the magnetic field are shown as filled-in traces in the two bottom panels. The vertical lines show the onset times of the electrojet activations

Accordingly, the magnetic field direction at both satellites strongly bent towards a more tail-like configuration and became nearly antiparallel along the tail axis between 0231 UT and 0239 UT. Such change in a more tail-like configuration could be due to the growth-phase signature in a dawnside magnetosphere, independently, developing outside the substorm region in the midnight sector. The timing of the westward electrojet developments and the change in the magnetic field configuration, however, suggests a more direct relationship exists between these two events. That is, the substorm current wedge which had already developed in the midnight region during this periods could likely be the direct cause of the distortion of the field in Equator-S and Geotail. Disturbance in the east-west component of the magnetic field, observed both at Equator-S and Geotail in both hemispheres, could be attributed to earthward

\section{EQUATOR-S 980425}

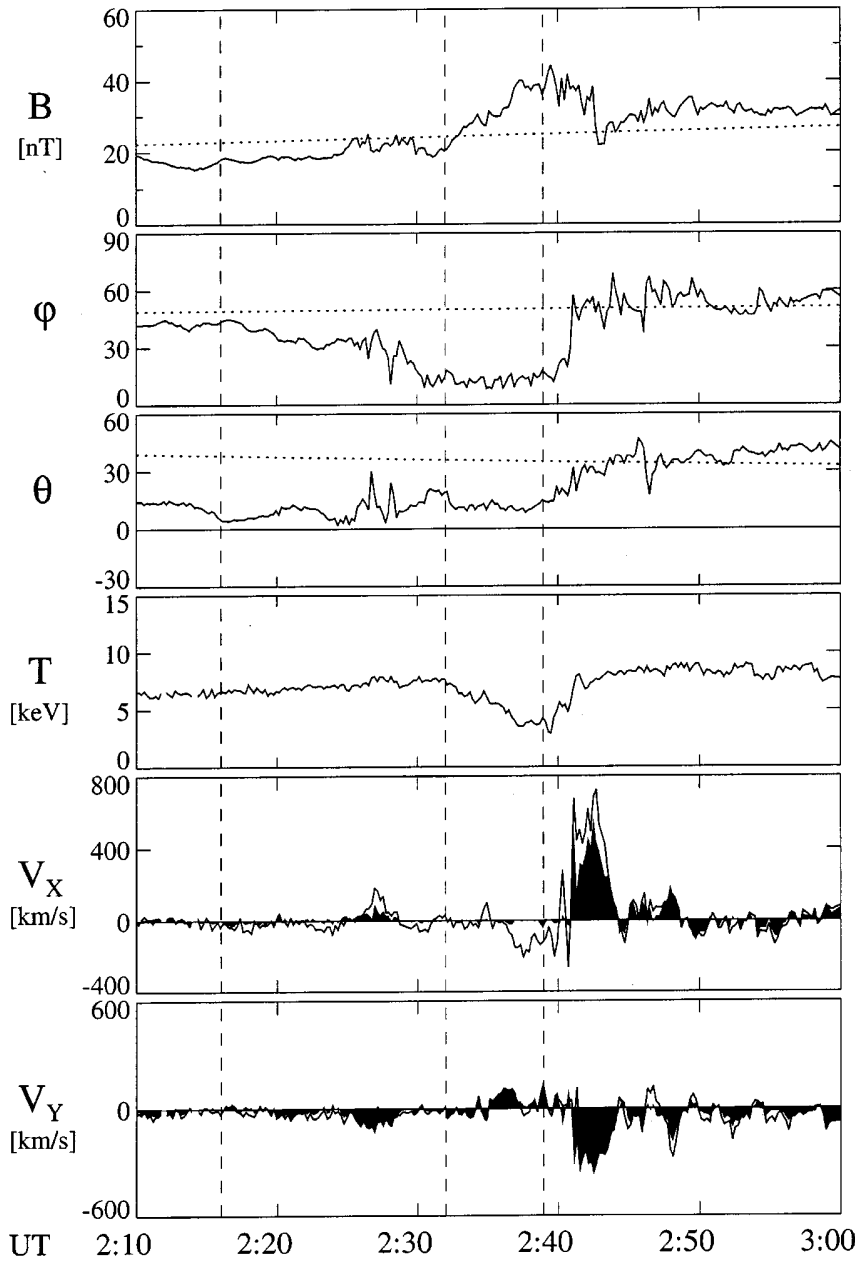

Fig. 7. Magnetic field and plasma data from Equator-S in the same format as Fig. 6

directed currents flowing earthward side (or equatorward side) of the two satellites.

In association with the poleward expansion of the electrojet in the IMAGE sector (0239 UT), magnetic field changes (decrease in $B$, enhancement in $\phi$ and $\theta$ ) accompanied by temperature increase and fast plasma flows were detected at both satellites. The changes in the magnetic field magnitude and $\theta$ and the increase in ion temperature at both satellites in the northern and southern hemisphere suggest that the plasma sheet expanded in association with the change in the magnetic field from a tail-like stretched to a more dipolar-like configuration. The change in the magnetic field signature was observed first at Equator-S before 0240 UT followed by Geotail at 0241 UT. Equator-S observed tailward flow along the field starting at around 0236 UT outside the plasma sheet. Following the entry into the plasma sheet, fast sunward and dawnward flows with a duration of about $4 \mathrm{~min}$ were detected by Equator-S from 0241 UT. The flows in the plasma sheet were mainly perpendicular to the field. Geotail also observed first tailward parallel flow near the lobe boundary and then fast flows perpendicular to the field, starting at 
0241 UT. The direction of the flow was tailward and duskward for about 3 min and changed to sunward and dawnward afterwards.

Figure 8 shows the magnetic field and plasma moments between 0230 and 0250 UT for Equator-S. To examine the field-aligned current disturbance, the data are transformed to a new coordinate system, which is close to the mean field-aligned coordinate system. In the near-field-aligned coordinates, the $Z$ component is identical to that in SM coordinates. The $X$ component is parallel to the projection of the average magnetic field direction on the $X-Y$ plane in the SM coordinates and is positive earthward. The $Y$ component closes the orthogonal system, and is expected to give the disturbance of the current along the average field direction. As a reference of the field direction we used the average field for the interval between 0200 and 0215 UT. The flows shown in Fig. 8 are components perpendicular to the ambient field. As discussed in the previous paragraph, the fast flow started at Equator-S around $0241 \mathrm{UT}$, when the plasma sheet expanded (starting from 0239 UT) and the temperature recovered to the presubstorm level. The fast flow is mainly in the $-Y$ $(\approx$ dawnward) direction in this coordinate system. In association with the dawnward flows, a positive disturbance in $B_{Y}$ can be seen.

Figure 9 shows the magnetic field and plasma moments for Geotail in the same format as Fig. 8.

\section{EQUATOR-S $\quad 980425$}

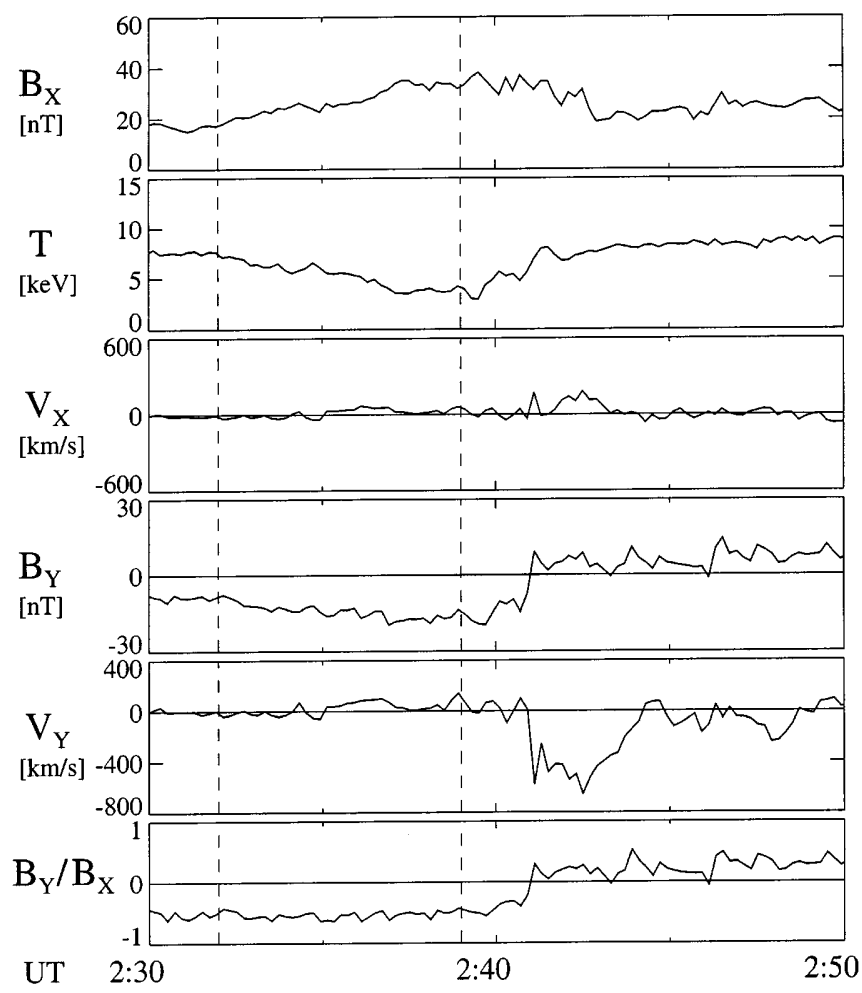

Fig. 8. Magnetic field and plasma moments between 0230 and 0250 UT for Equator-S in near-field-aligned coordinates (see text). The flows shown in the figure are components perpendicular to the field
Geotail also observed plasma sheet expansion from 0242 UT until about 0245 UT. The fast flow observed by Geotail is directed first in the $+Y(\approx$ duskward $)$ direction during the plasma sheet expansion and in the $-Y$ direction after $0245 \mathrm{UT}$, i.e., after the plasma sheet expansion. The positive $V_{Y}$ disturbance took place during the positive $B_{Y}$ disturbance, whereas the following negative $V_{Y}$ disturbance occurred during the period of negative $B_{Y}$ disturbance. This tendency is opposite to that observed by Equator-S.

\section{Discussion}

\subsection{Plasma sheet thinning}

Between the time interval of the initial substorm onset at 0205 UT and the local onset at 0239 UT, both satellites observed a gradual reconfiguration of the magnetic field and plasma sheet thinning, the latter becoming particularly pronounced after the 0232 UT global onset. This plasma sheet thinning is therefore different from those observed by Popielawaka et al. (1996) in the morning sector during the late recovery phase.

The temporal coincidence between the poleward expansion in the premidnight/midnight sector and the thinning of the morning side plasma sheet suggests a close relationship between the two events. In the geosynchronous orbit region, stressed magnetic field at longitudes just outside the current wedge was interpreted

\section{GEOTAIL 980425}

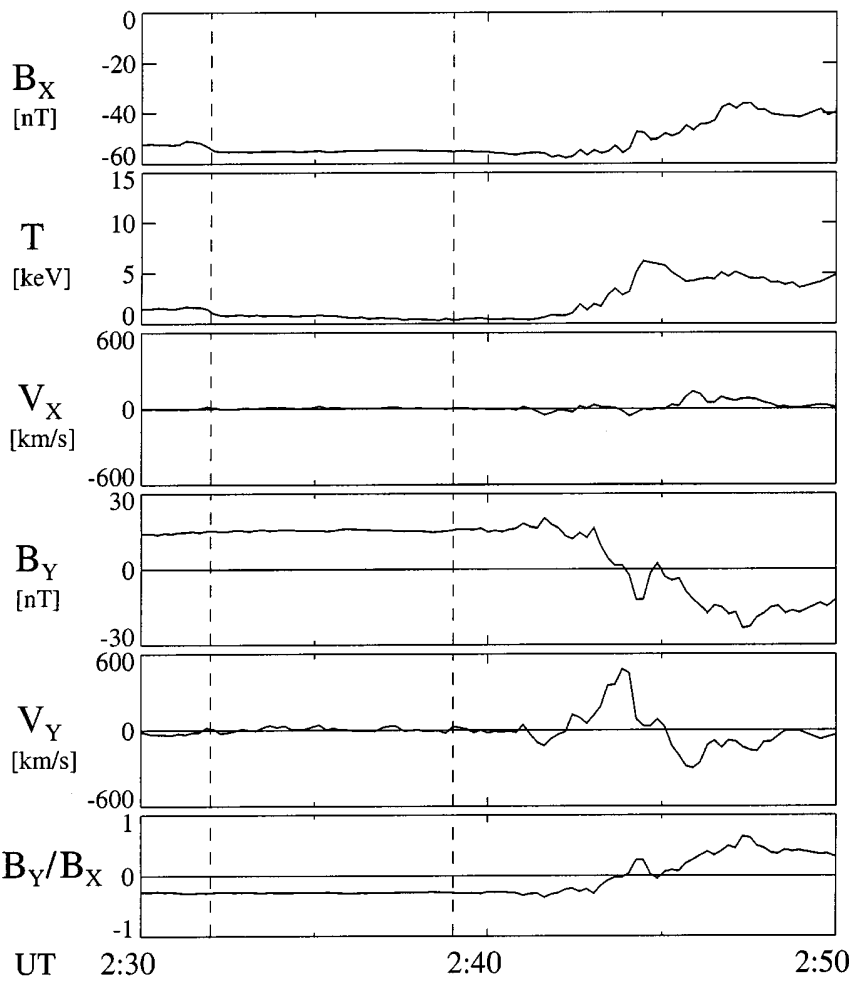

Fig. 9. Magnetic field and plasma moments between 0230 and 0250 UT for Geotail in the same format as Fig. 8 
to be due to the arrival of an injected diamagnetic proton cloud from the substorm current wedge region (Nagai, 1982a; Arnoldy and Moore, 1983), where the protons push away the magnetic field. In fact, Sergeev et al. (1998) reported an injection front observed by CRRES in the premidnight sector, with dispersionless proton flux increase and related diamagnetic decrease and dispersionless electron flux increase combined with increased $B$ (dipolarization). On the morningside, the electron injection region was observed to be more expanded than the ion injection region, opposite to the premidnight sector (Birn et al., 1997). An electron injection front, however, is expected to have a significantly lower temperature, and could therefore be less likely to produce similar diamagnetic effect to cause field distortion as reported on the eveningside. The thinning of the plasma sheet, observed in the Equator-S and Geotail therefore could be different than that observed at the premidnight region near the geosynchronous orbit.

The major component contributing to the observed reconfiguration in the magnetic field is not the increase in radial or decrease in northward component, which have been observed near geosynchronous orbit (Arnoldy and Moore, 1983; Nagai, 1982b). Rather, it is related to a distortion in the eastwest component. The east-west distortion of the field could be either due to a radial earthward component in the tail current or a downward field-aligned current flowing equatorward of the satellites. Geosynchronous observations reported east-west magnetic disturbances which was consistent with a downward field-aligned current in the morning sector outside the current wedge (Nagai, 1982a, b). The observed east-west component is opposite to that observed at geosynchronous orbit in the morning sector (Nagai, 1982a, b), but could be also interpreted as disturbance due to the downward field-aligned current if the current flows between geosynchronous orbits and the observed region. The westward electrojet development toward lower latitude than the satellite foot point locations during this time interval supports this interpretation. The $\theta$ for Geotail and Equator $\mathrm{S}$ gradually increased associated with the east-west field disturbance. This is an opposite sense to that observed at geosynchronous orbit, in which the northward component of the field decreased outside the current wedge (Nagai, 1982b). Both changes in $\theta$, however, could be interpreted to be due to an earthward motion of the tail current outside the current wedge (Nagai, 1982b), which can cause enhanced southward component earthward of the inner edge of the tail current (geosynchronous orbit) but can reduce the southward component close to the inner edge of the tail current (Equator-S and Geotail regions).

Figure 10a shows a schematic drawing of the observed characteristics on the morningside during the midnight sector substorm. Dipolarization region is indicated with gray region in the figure. Before the local dipolarization, we observed that the morningside plasma sheet experienced a significant distortion in the field toward a more tail-like orientation. Disturbances related to the current wedge formation in the night sector could be responsible for the configuration change in the morning sector.

\subsection{Fast flows}

We have observed fast east-west flows in the morningside plasma sheet as well as near the boundary of the plasma sheet in association with a local dipolarization following an onset of the global poleward expansion of the electrojet. While Equator-S near the center of the plasma sheet observed dawnward flows up to $600 \mathrm{~km} / \mathrm{s}$, Geotail closer to the boundary of the plasma sheet observed duskward and then dawnward flows in the course of the plasma sheet expansion. There are disturbances in the dawn-dusk component in the field associated with the flow. Figures $10 \mathrm{~b}$ and $\mathrm{c}$ illustrate the relationships between these flow and field during the plasma sheet expansion. The field distortion observed is consistent with a downward field-aligned current perturbation for both satellites. Based on the two-spacecraft observations, it is suggested that there is a flow shear as well as a magnetic shear structure near the boundary of the plasma sheet. Such relationships were obtained in the global MHD-simulation by Birn and Hesse (1996, Fig. 8). These authors found that the peak of the field aligned current is vertically collocated with the gradient of $B_{Y} / B_{X}$, and with the gradient in $V_{Y}$.

The fast dawn-dusk flows observed in this study correspond to an 20-25 mV/m electric field in the $X$ or $Z$ direction, if they are attributed to the $E \times B$ drift. Limited observations have shown such intense electric field (Aggson et al., 1983), but mainly in the dawn-dusk direction. The MHD-simulation predicts large electric fields (up to $20 \mathrm{mV} / \mathrm{m}$ ), concentrated mostly in the dipolarization region earthward of the reconnection region (Birn and Hesse, 1996). Such large electric field are again dawn-to-dusk directed, whereas the radial electric field (which is directed earthward in the morningside inner magnetosphere) is predicted to be about $5 \mathrm{mV} / \mathrm{m}$. (Birn, private communication, 1998). This is somewhat smaller than our observations for the dawnward flows.

It is surprising that Geotail observed also high-speed duskward flow preceding the dawnward flow. If it were a flow due to the electric field this corresponds to a tailward electric field up to $25 \mathrm{mV} / \mathrm{m}$. Such strong tailward electric field was not previously observed in the morningside plasma sheet and was not predicted in the models of the near-Earth reconnection and dipolarization process (Birn and Hesse, 1996). One explanation for the fast duskward flow could be the pressure gradient. In fact, the observed duskward flow was concentrated at the time when the temperature was increasing (see Fig. 9), which suggests that the pressure change could be important in explaining this flow observations. Since the field configuration near the end of the plasma sheet thinning was such that the field components in the $X-Y$ (SM) plane were almost antiparallel between Equator-S (northern hemisphere) and Geotail (southern hemisphere), we may simply assume that the contribution 
(a) during midnight substorm

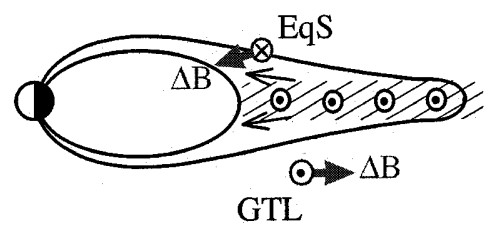

after global substorm expansion onset (b) 2:40-2:45 UT

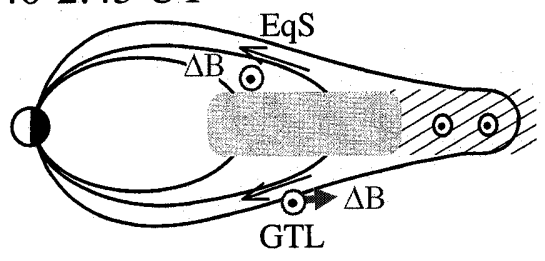

(c) 2:45 - 2:50 UT

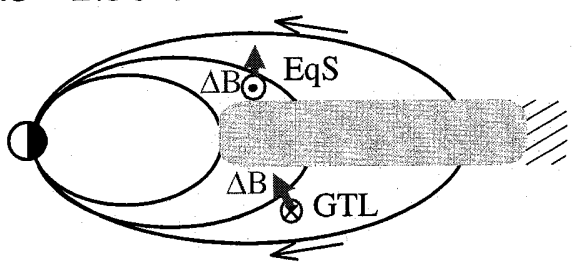

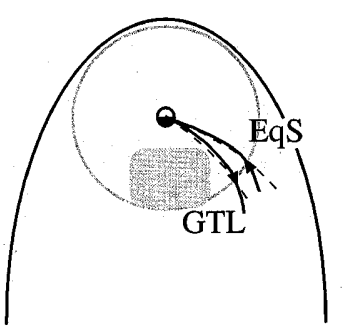
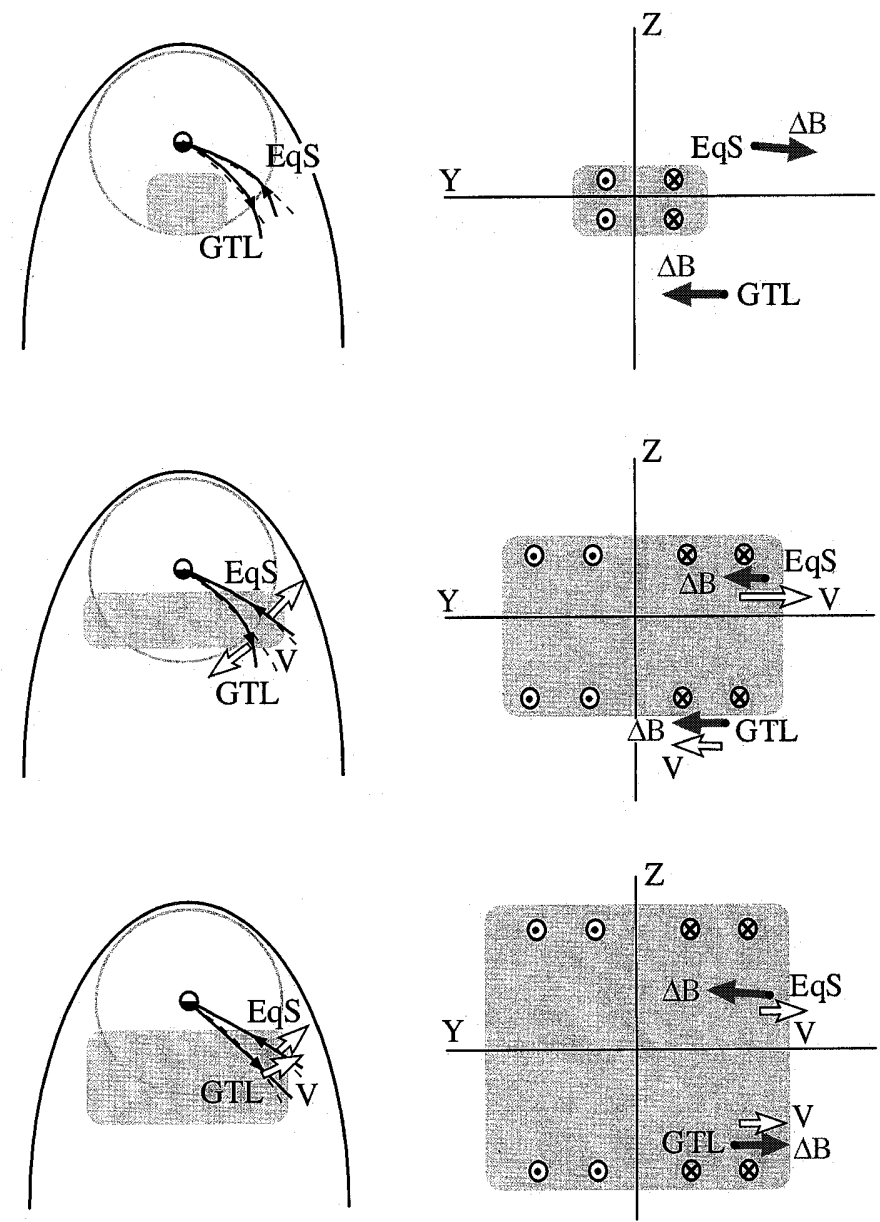

Fig. 10. A schematic figure of the observed characteristics on the morningside during (a) midnight sector substorm (b) the first $5 \mathrm{~min}$ and (c) the later $5 \mathrm{~min}$ of the morningside plasma sheet expansion. The substorm current wedge region is indicated by gray area. Magnetic field disturbances, which are the deviation from the magnetic field model (see text), are shown with thick dark gray arrows and circles, whereas the flow disturbances are shown with open arrows. Current directions are indicated with black thin arrows and

of the pressure gradient is mainly along the $Z$ component, i.e., $V_{Y} \approx(\Delta P / \Delta Z) / e n B \approx(\Delta P / \Delta t) / e n B V_{\text {exp }}$, where $V_{\text {exp }}$ is the plasma sheet expansion speed. By using the time difference between the crossing time of the highspeed dawnward flow regions of the two spacecraft (4 min) multiplied by the difference in the relative distance to the neutral sheet $\left(1.1 R_{E}\right), V_{\text {exp }}$ is estimated to be $28 \mathrm{~km} / \mathrm{s}$. Here the distance from the neutral sheet is calculated using an empirical model of Lopez (1990), from which we obtain the neutral sheet location at $Z_{S M}=-0.25 R_{E}$. Using the observed value from Geotail, $\Delta P / \Delta t \approx 0.3 \mathrm{nPa} / 30 \mathrm{sec}, B \approx 50 \mathrm{nT}$, and $n \approx 0.2 /$ $\mathrm{cm}^{-3}$, we obtain $V_{Y} \approx 148 \mathrm{~km} / \mathrm{s}$, which is about a factor of 3 smaller than the observed duskward flow. Since our assumption that a planar boundary normal to $Z$ axis expanding southward and northward overestimates the effective velocity to obtain the real spatial gradient $\Delta P /$ $\Delta Z$, it is likely that the pressure gradient is in fact responsible for the duskward flow observed by Geotail. Such a strong pressure gradient could be build up due to the injection of particles in the midnight plasma sheet circles. The left three panels show the expected change in the field configuration projected in the $X-Z$ plane. The middle three panels show the relationship between the field line bending and the flow disturbance in the equatorial plane. Here the projected field lines observed are indicated with the solid lines with an arrow (indicating the direction of the field). The dotted lines are the projected model field lines. The right three panels show the relationship between the flow and field disturbances in $Y-Z$ plane

region associated with the arrival of the main injection/ dipolarization front in the morning sector.

\section{Conclusion}

We have studied plasma flow and field characteristics in the morningside magnetosphere during a substorm with multiple intensifications. Observations from the two spacecraft, Equator-S and Geotail, identified plasma sheet thinning in the early morning sector associated with substorm expansion confined in the midnight and postmidnight sector. We interpret that such reconfiguration took place due to the current wedge in the midnight sector. That is, a downward field-aligned current and a distorted tail current causes the plasma sheet thinning in the morning sector.

Unusually high-speed flow bursts with significant dawn-dusk components were detected at both satellites accompanied by a global expansion of the plasma sheet. Strong flow shear is identified in the morning sector, 
which is likely to be responsible for the downward field aligned current. These high-speed flows could be approximately understood by an induced electric field at the local dipolarization region and/or by an enhanced pressure gradient associated with the injection in the midnight plasma sheet, although more comprehensive information on spatial/temporal changes in the field and plasma parameters is needed to confirm quantitatively these mechanisms.

Acknowledgements. Equator-S was financially supported via grant $500 \mathrm{C} 94024$ by the German Space Agency, DARA (now DLR). The IMAGE magnetometer data used in this paper were collected as a German-Finnish-Norwegian-Polish project conducted by the Finnish Meteorological Institute. The authors are especially grateful to the following individuals and institutions for providing data: T. Hughes, T. Iyemori, A. Kadokura, O. Rusmussen, the Canadian Space Agency, the Danish Meteorological Institute, the Geological Survey of Canada, the WDC-C2, and A. Viljanen for the electrojet boundary estimates. The work at the University of Iowa was supported by the National Aeronautics and Space Administration under NAG5-7712.

\section{References}

Aggson, T. L., J. P. Heppner, and N. C. Maynard, Observations of large transient magnetospheric electric fields, J. Geophys. Res., 88, 3981, 1983.

Arnoldy, R. L., and T. E. Moore, Longitudinal structure of substorm injections at synchronous orbit, J. Geophys. Res., 88, 6213-6220, 1983.

Baumjohann, W., The near-Earth plasma sheet: an AMPTE/IRM perspective, Space Sci. Rev., 64, 141, 1993.

Birn, J., and M. Hesse, Details of current disruption and diversion in simulations of magnetotail dynamics, J. Geophys. Res., 101, 15345-15358, 1996.

Birn, J., M. F. Thomsen, J. E Borovsky, G. D. Reeves, D. J. McComas, and R. D. Belian, Characteristic plasma properties during dispersionless substorm injections at geosynchronous orbit, J. Geophys. Res., 102, 2309-2324, 1997.

Fairfield, D. H., T. Mukai, A. T. Y. Lui, C. A. Cattell, G. D. Reeves, T. Nagai, G. Rostoker, H. J. Singer, M. L. Kaiser, S. Kokubun, A. J. Lazarus, R. P. Lepping, M. Nakamura, J. T. Steinberg, K. Tsruda, D. J. Williams, and T. Yamamoto, Geotail observations of substorm onset in the inner magnetotail, J. Geophys. Res., 103, 103-117, 1998.

Fornacon, K.-H., H. U. Auster, E. Georgescu, W. Baumjohann, K.H. Glaßmeier, J. Rustenbach, and M. Dunlop, The magnetic field experiment onboard Equator-S and its scientific possibilities, Ann. Geophys. 17, 1999.

Frank, L. A., J. B. Sigwarth, J. D. Craven, J. P. Cravens, J. S. Dolan, M. R. Dvorsky, P. K. Hardebeck, J. D. Harvey, and D. Müller, The visible imaging system (VIS) for the Polar spacecraft, Space Sci. Rev. 71, 297, 1995.
Greenwald R. A., W. Weiss, E. Nielsen, and N. R. Thomas, STARE: a new radar auroral backscatter experiment in northern Scandinavia, Radio Sci., 13, 1021-1039, 1978.

Kistler, L.M., B. Klecker, V. K. Jordanova, E. Möbius, M. A. Popecti, D. Patel, J. A. Savaud, H. Rème, A. M. DiLellis, A. Korth, M. McCarthy, R. Cerulli, M. B. Bavossano-Catlaneo, L. Eliasson, C. W. Carlson, G. K. Parts, G. Paschmann, W. Baumjohann, G. Haerendel, Testing electric field models using ion energy spectra from the Equator-S ion composition (ESIC) instrument, Ann. Geophysicae, 17, 1999.

Kokubun, S., T. Yamamoto, M. H. Acuna, K. Hayashi, K. Shiokawa, and H. Kawano, The GEOTAIL magnetic field experiment. J. Geomagn. Geoelec., 46, 7-21, 1994.

Kopanyi, V., and A. Korth, Energetic particle dropouts observed in the morning sector by the Geostationary Satellite GEOS-2, Geophys. Res. Lett., 22, 73-76, 1995.

Lopez, R. E., The position of the magnetotail neutral sheet in the near-Earth region, Geophys. Res. Lett., 17, 1617-1620, 1990.

Lühr, H., The IMAGE magnetometer network, STEP Int. Newsl., 4, 4-6, 1994.

McPherron, R. L., C. T. Russell, and M. P. Aubry, Satellite studies of magnetospheric substorms on August 15, 1968, 9, Phenomenological model of substorms, J. Geophys. Res., 78, 3131, 1973.

Mukai, T., S. Machida, Y. Saito, M. Hirahara, T. Terasawa, N. Kaya, T. Obara, M. Eiri, and A. Nishida, The low energy particle (LEP) experiment onboard the Geotail satellite, J. Geomagn. Geoelec., 46, 669-692, 1994.

Nagai, T., Local time dependence of electron flux changes during substorms derived from multi-satellite observation at synchronous orbit, J. Geophys. Res., 87, 3456-3468, 1982a.

Nagai, T., Observed magnetic substorm signatures at synchronous altitude, J. Geophys. Res., 87, 4405-4417, 1982 b.

Nagai, T., An empirical model of substorm-related magnetic field variations at synchronous orbit, in Magnetospheric Substorms, Geophys. Monogr., 64, ed. J. R. Kan, T. A. Potemra, S. Kokubun, T. Iijima, 91-95, 1991.

Nagai, T., and S. Machida, Magnetic reconnection in the nearEarth magnetotail, in New perspectives on the Earth's magnetotail, Geophys. Monogr., 105, ed. A. Nishida, D. N. Baker, S. W. H. Coweley, 211-224, 1998.

Popielawska, B., P. Koperski, R. Lundin, A. Zakharov, and J. Grygorczuk, Substorms with multiple intensifications: Postonset plasma sheet thinings in the morning sector observed by Prognoz-8, J. Geophys. Res., 23, 629-632, 1996.

Rostoker, G., J. C. Samson, F. Creutzberg, T. J. Hughes, D. R. McDiarmid, A. G. McNamara, A. Vallance Jones, D. D. Wallis, and L. L. Cogger, CANOPUS - A ground based instrument array for remote sensing the high latitude ionosphere during the ISTP/GGS program, Space Sci. Rev., 71, $743-760,1995$.

Sergeev, V. A., M. A. Shukhtina, R. Rasinkangas, A. Korth, G. D. Reeves, H. J. Singer M. F. Thomsen, and I. I. Vagina, Event study of deep energetic particle injections during substorm, $J$. Geophys. Res., 103, 9217-9234, 1998.

Tsyganenko N. A., Magnetospheric magnetic field model with a warped tail current sheet, Planet. Space Sci., 37, 5, 1989. 